\title{
Club cells and CC16: another "smoking gun"? (With potential bullets against COPD)
}

\author{
Lucie Knabe ${ }^{1}$, Aurélie Fort ${ }^{2}$, Pascal Chanez $^{3}$ and Arnaud Bourdin ${ }^{1,2}$
}

Affiliations: ${ }^{1}$ U1046 INSERM, UMR9214 CNRS, Montpellier University, Montpellier, France. ${ }^{2}$ Dept of Respiratory Diseases, CHRU Montpellier, Montpellier, France. ${ }^{3}$ Dept of Respiratory Diseases APHM, INSERM CNRS U 1067, UMR7333, Aix-Marseille University, Marseille, France.

Correspondence: Arnaud Bourdin, Dept of Respiratory Diseases, 371 Av Doyen Giraud, 34295 Montpellier Cedex 5, France. E-mail: a-bourdindachu-montpellier.fr

0 @ERSpublications

Greater susceptibility of knockout CC16 mice to cigarette smoking gives insight regarding a potential player in COPD http://ow.ly/KhCMa

Chronic obstructive pulmonary disease (COPD) remains a challenge for clinicians and scientists, as no currently available treatment can significantly change the natural history of the disease. Accelerated lung function decline and recurrent episodes of exacerbations are thought to play critical roles in precipitating patients towards comorbid conditions, long-term oxygen supplementation dependency, and finally death. Currently, the underlying paradigm counterbalances alveolar wall destruction with peribronchiolar fibrosis, the latter being hypothesised to precede the former [1]. Although small airways are now largely recognised as the critical zone of disease initiation and progression [2], very few histological and biological properties specific to this compartment in humans have been highlighted to explain this phenomenon.

Club cells, identified during the 19th century, are one of these targets and thorough efforts have aimed at identifying them as another "smoking gun" candidate [3]. CC16, a 15.8-kDa protein, is secreted by these nonciliated bronchiolar cells and is supposed to have anti-inflammatory properties. Confusing roles in airway homeostasis maintenance have been attributed both to the protein and to the cell [4], since these cells are commonly identified by the protein. CC16 could act through the direct binding of inhaled toxicants within its hydrophobic pocket for example, while the club cell may detoxify inhaled noxious agents through the expression of naphthalene-targeted CYP2F2 cytochrome [5] and play a role of accessory resident stem cell [6].

Serum CC16 level has been shown as a potential biomarker of accelerated lung function decline in a very large cohort [7]. CC16 polymorphism and local deficiency on the one hand, and a decreased number of club cells on the other hand, were reported as features of COPD [8, 9], as confirmed by LAUCHO-CONTRERAs et al. [10] in the current issue of the European Respiratory Journal. In previous studies, exogenous CC16 showed pharmacological properties that could decrease excess airway inflammation and mucus production in ex vivo models [11-13]. However, CC16 has not demonstrated physiological properties, as shown in a prior report on CC16-deficient mice, which were not more susceptible to changes induced by cigarette smoke [14].

The paper by LAUChO-CONTRERAS et al. [10] has reported novel and important observations of knockout CC16 mice exposed to 6 months of smoking. They not only observed an increased susceptibility of the knockout animals to emphysema and peribronchiolar fibrosis, but also unravelled potential mechanisms of action of CC16 involved in COPD development. These knockout mice exposed to cigarette smoke exhibited exaggerated airway inflammation, increased alveolar septal and bronchial cell apoptosis and goblet cell metaplasia. Conversely, increased nuclear factor- $\kappa \mathrm{B}$ levels of activation were recorded. These findings support the hypothesis of McDonough et al. [1], which states that bronchiolar obstruction may

Received: Jan 212015 | Accepted after revision: Feb 182015

Conflict of interest: None declared.

Copyright @ERS 2015 
precede emphysema. Importantly, these animals could be rescued from the harmfulness of cigarette exposure by overexpressing CC16 through inhaled transfected adenovirus, and this represents a therapeutic perspective.

These promising observations deserve important comments. First, the exact mechanism of action of CC16 is in fact not firmly established here, since ex vivo air-liquid interface cultures of the airway epithelium of knockout mice did not behave differently from the wildtype-derived cells, and demonstrated no exaggerated apoptosis. CC16 may act through a direct intercellular paracrine action [15] or direct inhaled toxicant neutralisation [5], but unfortunately, this was not investigated in the present study. Phospholipase A2 had been considered a possible target for CC16 but this was not confirmed. The identification of a receptor for CC16 would represent the next step to better understand this hypothesis. Since CYP2F2 disappeared with CC16 knockout in the present study, this raised the question of whether interfering with the protein also interfered with the cell, and subsequently, the question of whether protein or cell was the most important player in the field [16].

Secondly, exposure to cigarette smoke required high levels to reach these findings, in contrast with a previous attempt using the same animals [14]. Indeed, this does not at all predict the extent to which CC16 is important in regard to COPD susceptibility. Furthermore, knowledge about human and rodent airway epithelia is not perfectly corroborating, since cells expressing CC16 are predominant throughout the rodent airway tree [17].

Recently, CC16-expressing cells from the bone marrow were shown to participate in airway epithelial regeneration [16]. With regard to the human therapeutic perspective, it is of great importance to identify the optimal timing of initiation and especially whether it should occur before or after smoking cessation. This debate reaches beyond biology but the answer is a prerequisite for best ethical decision making when considering cigarette smoking as an addiction.

Last but not least, this study does not really improve understanding of why CC16 polymorphisms would be important in increasing COPD susceptibility as identified by large genome-wide association study initiatives. It provides an important insight regarding a potential key player in the injury/repair imbalance elicited at the epithelial surface. However, the dynamic regulation of CC16 expression and release is not allowed by such a model, for example during an exacerbation, and this is potentially important in the futuristic therapeutic perspective of exogenous supplementation in humans.

\section{References}

1 McDonough JE, Yuan R, Suzuki M, et al. Small-airway obstruction and emphysema in chronic obstructive pulmonary disease. N Engl J Med 2011; 365: 1567-1575.

2 Burgel PR, Bourdin A, Chanez P, et al. Update on the roles of distal airways in COPD. Eur Respir Rev 2011; 20: $7-22$.

3 Crystal RG. Airway basal cells. The "smoking gun" of chronic obstructive pulmonary disease. Am J Respir Crit Care Med 2014; 190: 1355-1362.

4 Bernard A. Club cell protein and chronic obstructive pulmonary disease progression: the unrealized potential of a peripheral lung biomarker. Am J Respir Crit Care Med 2014; 189: 614-615.

5 Stripp BR, Lund J, Mango GW, et al. Clara cell secretory protein: a determinant of PCB bioaccumulation in mammals. Am J Physiol 1996; 271: L656-L664.

6 Giangreco A, Reynolds SD, Stripp BR. Terminal bronchioles harbor a unique airway stem cell population that localizes to the bronchoalveolar duct junction. Am J Pathol 2002; 161: 173-182.

7 Vestbo J, Edwards LD, Scanlon PD, et al. Changes in forced expiratory volume in 1 second over time in COPD. $N$ Engl J Med 2011; 365: 1184-1192.

8 Kim DK, Cho MH, Hersh CP, et al. Genome-wide association analysis of blood biomarkers in chronic obstructive pulmonary disease. Am J Respir Crit Care Med 2012; 186: 1238-1247.

9 Bourdin A, Kotsimbos T, Nguyen K, et al. Non-invasive assessment of small airway remodelling in smokers. COPD 2010; 7: 102-110.

10 Laucho-Contreras ME, Polverino F, Gupta K, et al. Protective role for club cell secretory protein-16 (CC16) in the development of COPD. Eur Respir J 2015; 45: 1544-1556.

11 Gamez AS, Gras D, Petit A, et al. Supplementing defect in club cell secretory protein attenuates airway inflammation in COPD. Chest 2014 [In press DOI: 10.1378/chest.14-1174].

12 Tokita E, Tanabe $\mathrm{T}$, Asano $\mathrm{K}$, et al. Club cell $10-\mathrm{kDa}$ protein attenuates airway mucus hypersecretion and inflammation. Eur Respir J 2014; 44: 1002-1010.

13 Hiemstra PS, Bourdin A. Club cells, CC10 and self-control at the epithelial surface. Eur Respir J 2014; 44: 831-832.

14 Park HY, Churg A, Wright JL, et al. Club cell protein 16 and disease progression in chronic obstructive pulmonary disease. Am J Respir Crit Care Med 2013; 188: 1413-1419.

15 Reynolds SD, Reynolds PR, Snyder JC, et al. CCSP regulates cross talk between secretory cells and both ciliated cells and macrophages of the conducting airway. Am J Physiol Lung Cell Mol Physiol 2007; 293: L114-L123.

16 Bustos ML, Mura M, Hwang D, et al. Depletion of bone marrow CCSP-expressing cells delays airway regeneration. Mol Ther 2015; 23: 561-569.

17 Boers JE, Ambergen AW, Thunnissen FB. Number and proliferation of clara cells in normal human airway epithelium. Am J Respir Crit Care Med 1999; 159: 1585-1591. 